IRA-International Journal of Education \& Multidisciplinary Studies

ISSN 2455-2526; Vol.03, Issue 03 (2016)

Institute of Research Advances

http://research-advances.org/index.php/IJEMS

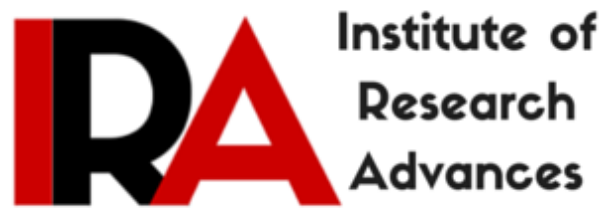

\title{
Exploring the Suicide Phenomenon: Basis for the Development of a Counseling Program
}

Bonna S. Palma, Ed.D.

West Visayas State University

La Paz, Iloilo City, Philippines.

DOI: http://dx.doi.org/10.21013/jems.v3.n3.p25

\section{How to cite this paper:}

Palma, B. (2016). Exploring the Suicide Phenomenon: Basis for the Development of a Counseling Program. IRA International Journal of Education and Multidisciplinary

Studies (ISSN 2455-2526), 3(3). doi:http://dx.doi.org/10.21013/jems.v3.n3.p25

(C) Institute of Research Advances

\section{(cc) EY-No}

This works is licensed under a Creative Commons Attribution-Non Commercial 4.0 International License subject to proper citation to the publication source of the work.

Disclaimer: The scholarly papers as reviewed and published by the Institute of Research Advances (IRA) are the views and opinions of their respective authors and are not the views or opinions of the IRA. The IRA disclaims of any harm or loss caused due to the published content to any party. 


\section{ABSTRACT}

This qualitative study conducted in May 2010 sought to find out the characteristics of the eight suicide attempters, the precipitating factors that trigger them to attempt suicide, their coping mechanisms, the role of significant others in their health, the insights gained from the experience and the post intervention services availed after the incident. Data gathering strategies used were the researcher-made interview guide and the focusedgroup discussions using photo essay which summarized the commonalities among the informants. The informants were college students doing the usual activities of normal teenagers with varying circumstances of family background and economic status in life; they also experienced hardships, difficulties, pain, anger, joy, and happiness just like any average teenager but they lack the ability to cope with the overwhelming situations and problems; they experienced moments of emptiness and psychological hopelessness; and they also experienced severe physical maltreatment and varied emotional abuse. Strained or failed romantic relationship had added to the realization of their suicidal ideations, but then, they were able to cope with the aftermath by employing some coping strategies. Their friends became their shoulders to lean on; their immediate family members and relatives were their wings who offered financial, moral and emotional support; and their teachers and classmates were their lifeline. The informants' painful experiences of their attempt to end their lives helped them gain insights and realized that there is more to life. Among the eight informants, only one received a formal post intervention service, while others received the usual care and acceptance from the significant others who accepted them for what happened and what they had done.
\end{abstract}

Keywords: counseling, Diathesis-stress model, explore, phenomenon, program, suicide

Suicide (Latin suicidium, from sui caedere, "to kill oneself") is the intentional taking of one's own life. It may occur for a number of reasons, including depression, shame, guilt, desperation, physical pain, emotional pressure, anxiety, financial difficulties, or other undesirable situations (Barlow and Durand, 1998).

The World Health Organization (WHO) noted that over 1 million people commit suicide every year, and that is one of the leading causes of death among teenagers and adults under 25 . There are an estimated 10 to 20 million nonfatal attempted suicides every year worldwide. The organization reports that every year about 1 million people die by suicide. That comes to around 3,000 deaths a day or 1 death every 40 seconds. In the past 45 years, the WHO says suicide rates have increased by $60 \%$ worldwide, and it predicts these deaths will rise to 1.5 million by 2020 .

In the Philippines, at least 100,000 adolescents commit suicide every year, while 584 of deaths from suicides reported by the Department of Health were among teens aged 15 to 19 between 2001 and 2003 .

According to Hurlock (1982), the first evidence of the importance of parent-child relationship is the effect of emotional deprivation during the early years of life. Babies who are institutionalized and thus deprived of normal opportunities to express their love or to be loved by others become quiet, listless, and unresponsive to the smiles and attempts to show affection on the part of others. They show extreme forms of temper, as if seeking attention, and they give the general impression of unhappiness.

Another theory, the Anomie Theory, is that of the French sociologist Emile Durkheim. He argues that suicide rates are related to social integration - that is, the degree to which an individual feels part of a larger group. Durkheim found suicide is more likely when a person lacks social bonds or has relationships disrupted through a sudden change in status, such as unemployment.

Another theory that will help people clearly understand suicide is with the use of the diathesis-stress model. This model has been reformulated in the last 20 years as the stress-vulnerability-protective factors model, particularly by Dr. Robert P. Liberman and his colleagues in the field of psychiatric rehabilitation (Barlow and Durand, 1998).

In the diathesis-stress model, a biological or genetic vulnerability or predisposition (diathesis) interacts with the environment and life events (stressors) to trigger behaviors or psychological disorders. The greater the underlying vulnerability, the less stress is needed to trigger the behavior or disorder. Conversely, where there is a smaller genetic contribution, greater life stress is required to produce the particular result. 
This study aimed to delve into the suicide phenomenon that has remained a major problem worldwide. Specifically, the study sought answers to the following questions:

1. Who are the suicide attempters? What are their characteristics?

2. What are the precipitating factors that trigger an individual to attempt suicide?

3. How do suicide attempters cope with the aftermath?

4. What is the role of significant others in their healing?

5. What insights do the informants have gained from their suicide attempts? How do these affect their personality?

6. Were there some post-intervention services offered or availed of after the attempt?

\section{The Suicide Phenomenon}

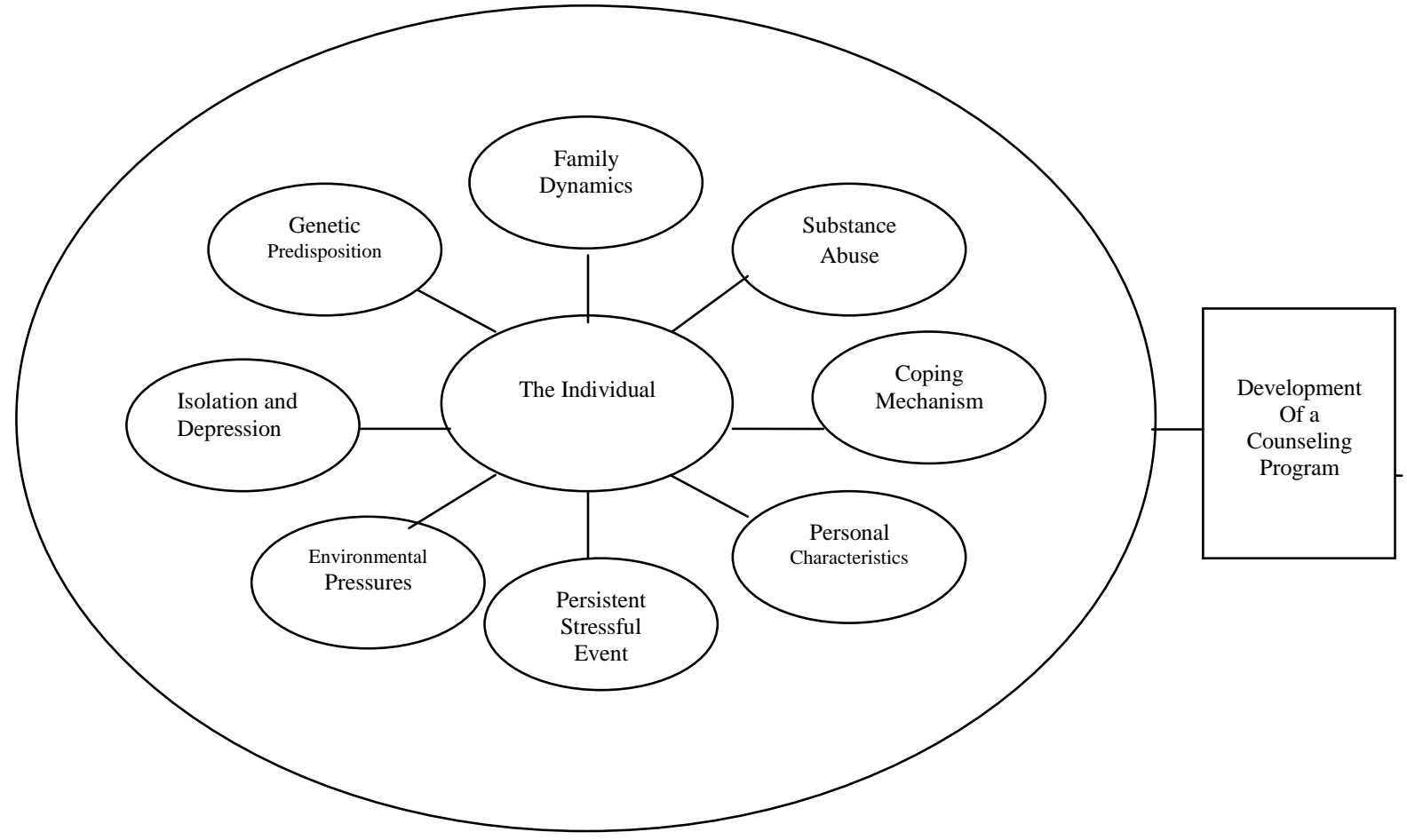

Figure 1. The suicide phenomenon and the factors that surround the individual.

This qualitative research delved into the "suicide phenomenon" that has remained a major health problem worldwide. This study included eight suicide attempters from the province and city of Iloilo and the provinces of Guimaras. Antique and Negros Occidental. They belonged to the following categories: Adolescent (12-18 years old) and Early Adult (19-34 years old). The informants were mainly people who had attempted suicide but were very much fortunate to be alive.

This study employed the qualitative research design, specifically grounded theory. Grounded theory was developed by two sociologists, Barney Glaser and Anselm Strauss. It is a systematic generation of theory from data that contains both inductive and deductive thinking. One goal of a GT is to formulate hypotheses based on conceptual ideas. GT does not aim for the "truth" but to conceptualize what's going on by using empirical data (Glaser \& Strauss, 1967).

The data collection strategies were informant observation, in-depth interviews, and focused-group discussion. The informant observation is a method which assumes that, in order to understand the world first hand, you must participate yourself rather than just observe at a distance (Silverman, 2010). In the triangulation of data, participant interviews, documents from guidance counselors, testimonial from relatives, teachers, and close friends were gathered to further validate the observations made. 


\section{Research Design and Methodology}

This qualitative research aimed to delve into the "suicide phenomenon" that has remained a major health problem worldwide. This study involved eight suicide attempters from the province and City of Iloilo and the provinces of Guimaras, Antique, and Negros Occidental. They were classified into two groups: Adolescence (12-18 years old), and Early Adulthood (19-34years old).

This study employed the qualitative research design, specifically grounded theory. It is a systematic generation of theory from data that contain both inductive and deductive thinking. One goal of GT is to formulate hypotheses based on conceptual ideas. GT does not aim for the "truth" but to conceptualize what is going on by using empirical data (Glaser \& Strauss, 1967).

The data collection strategies were informant observation, in-depth interviews, and focused-group discussion. In the triangulation of data, participants' interviews, documents from guidance counselors, testimonies from relatives, teachers, and close friends were gathered to further validate the observations made. The researcher-made interview gathered data on the informant's painful experiences, how they tried to cope with the situation, the significant others who guided and support them, what they are presently doing, and what their future plans and ambitions are. The research instrument by Pineda (2007) was used to determine whether the informants' information were consistent and reliable. The questions were translated in Hiligaynon and the informants were allowed to answer in the language that they were most comfortable with.

In the focused-group discussion, a photo essay was used to guide the discussion and to look for commonalities of experience. The informants were also made to freely express their innermost thoughts and feelings, fears, anger, resentments, regrets, happiness, hopes and aspirations.

All informants used a pseudonym. Verbal and non-verbal communication were observed and documented. Words were recorded and noted verbatim. Facial expressions especially the eyes, head, hand and feet gestures were noted.

Interviews usually ended with the assurance of the confidentiality of disclosed information, of seeing each other again or of informing through text if there will be changes on schedules of next meeting and of expression of concern, empathy and appreciation to the informants for the trust given.

\section{The Informants}

The study included eight suicide attempters. Four of them were males and four were females with ages ranging from 17 to 25 years old, were college students and one is an only child. Most of the informants came from economically sufficient families. They come from the city and province of Iloilo and the provinces of Antique and Negros Occidental specifically, from the municipalities of Pototan and Dumangas, Iloilo; the district of La Paz and Jaro, and Buenavista, Guimaras, San Jose, Antique and Victorias, Negros Occidental.

The informants showed feeling of depression, pervasive sadness and feeling of hopelessness. They exhibited inability to concentrate and were very much preoccupied of the thoughts of suicide. They showed erratic behaviors and also experienced fatigue, restlessness and difficulty in their sleeping habits. They experienced "tunnel vision" for they only think about their pain and helplessness. They felt ignored and rejected and believed that suicide is a permanent solution to a temporary problem.

They showed emotional instability, experience identity crises, have poor coping mechanisms, lack of focus and goals in life, pessimistic and depressed due to being preoccupied by problems, anger and sadness resulting to conflict with other people and unsupportive environment.

They experienced moments of emptiness and hopelessness. They also experienced physical abuse, varied emotional neglect like parents showing favoritism to other siblings, verbal assaults from parents, feelings of betrayal such as a father having an affair with another woman, abandoned by either the father or the mother, lack of communication with family members, etc. Likewise, strained or failed romantic relationship had added to the realization of their suicidal ideations. 
Table 1

The Informants

\begin{tabular}{|c|c|c|c|c|c|c|c|}
\hline NAME & SEX & AGE & $\begin{array}{l}\text { BIRTH } \\
\text { RANK }\end{array}$ & COURSE & $\begin{array}{l}\text { YR } \\
\& \\
\text { SEC }\end{array}$ & SCHOOL & ADDRESS \\
\hline 1. J.M.T. & $\mathrm{M}$ & 17 & $\begin{array}{l}2^{\text {nd }} \text { child } \\
(3 \text { boys })\end{array}$ & $\begin{array}{l}\text { Cruise } \\
\text { Ship }\end{array}$ & $\begin{array}{l}1^{\text {st }} \\
\text { Year }\end{array}$ & Private & Guimaras \\
\hline 2. Zach & $\mathrm{M}$ & 19 & $\begin{array}{l}\text { Eldest } \\
\text { (3 Boys) }\end{array}$ & BSIT & $\begin{array}{l}2^{\text {nd }} \\
\text { Year }\end{array}$ & Private & $\begin{array}{l}\text { Negros } \\
\text { Occidental } \\
\end{array}$ \\
\hline 3.Spooky & $\mathrm{F}$ & 25 & Eldest & $\begin{array}{l}\text { AB } \\
\text { Psychology }\end{array}$ & $\begin{array}{l}4^{\text {th }} \\
\text { Year }\end{array}$ & Private & $\begin{array}{l}\text { Jaro, } \\
\text { I.C. }\end{array}$ \\
\hline 4. Grease & $\mathrm{F}$ & 19 & $\begin{array}{l}\text { Youngest } \\
\text { of } 5 \\
\text { ( } 2 \text { boys, } 3 \\
\text { Girls) }\end{array}$ & BSN & $\begin{array}{l}3^{\text {rd }} \\
\text { Year }\end{array}$ & Private & $\begin{array}{l}\text { La Paz, } \\
\text { I.C. }\end{array}$ \\
\hline 5. Kim & $\mathrm{F}$ & 22 & $\begin{array}{l}\text { Eldest } \\
\text { among } 2 \\
\text { (boy) }\end{array}$ & BSN & $\begin{array}{l}1^{\text {st }} \\
\text { Year }\end{array}$ & Private & $\begin{array}{l}\text { City } \\
\text { Proper }\end{array}$ \\
\hline 6. Mack & $\mathrm{M}$ & 20 & $\begin{array}{l}2^{\text {nd }} \\
\text { among } 6\end{array}$ & Education & $\begin{array}{l}4^{\text {th }} \\
\text { Year }\end{array}$ & Public & Dumangas \\
\hline 7. Champ & $\mathrm{M}$ & 19 & $\begin{array}{l}\text { Only } \\
\text { child }\end{array}$ & $\begin{array}{l}\text { BS } \\
\text { Accountancy }\end{array}$ & $\begin{array}{l}2^{\text {nd }} \\
\text { Year }\end{array}$ & Private & Antique \\
\hline 8. Apple & $\mathrm{F}$ & 18 & $\begin{array}{l}3^{\text {rd }} \\
\text { among } 5\end{array}$ & Education & $\begin{array}{l}2^{\text {nd }} \\
\text { Year }\end{array}$ & Public & Pototan \\
\hline
\end{tabular}

\section{Findings}

After their suicide attempt, the suicide attempters resorted to drinking alcoholic beverages, smoking, and using prohibited drugs. They found temporary refuge in attending parties, going to disco houses, computer stations and internet cafes. Eventually, they were able to cope with the aftermath with the presence of some protective factors such as the love and acceptance of understanding family members and by employing some coping strategies such as: talking and opening up their worries and fears with the people they referred to as "significant others" like their lolas, aunts, and siblings; getting advice and support from their teacher, and laughing and mingling with their classmates.

In general, the attempters found their immediate family and relatives as their wings who offered financial, moral and emotional support, care, and attention; their friends became their shoulders to lean on and buddies to hang out; their teachers and their classmates were their lifeline as they were supported wholeheartedly and accepted for who they are - warts and all.

Their painful experience of the attempt to end their lives helped them gain insights and realized that there is more to life than wallow in self-pity and ending it prematurely. They started to dream of having a better life, finish their studies, have a stable job, create and build better relationships with their parents, siblings, classmates, and the people around them. They also hope to have their own family in the future, as well as help and send their siblings to school and live a life free from pain, fear and depression.

Among the eight informants, only one received a formal post intervention service, while others received the special care and attention from the significant others who understood and accepted them in spite of what happened and what they have done.

\section{Based on the findings, the following conclusions were drawn:}

The suicide attempters come from different places, regardless of birth order and circumstances in life. They are considered normal individuals who experience pain, hardships, difficulties, happiness and joy. However, they perceived their family circumstances and problems as overwhelming and beyond their ability to cope; thus, making them emotionally depressed and hopeless, causing them to resort to attempt suicide.

Suicide may have been an escape from their present predicament and troubled situation which is most common of the eight informants. Their perception of their difficult situation and experiences confronting them is somehow different as compared to 
others who did not attempt suicide. They seem to lack the ability and resources to cope with the demands of the situation. Their way of escaping from the aversive situations and obtain respite from a distorted state of mind is by attempting suicide as a way to put an end to everything including their suffering.

One reason could have been due to the lack of affection and affirmation from their parents. According to Bowlby (1969), the type of attachment children have with their parents have long-lasting effects. Infants with secure attachments have closer friendships and better social skills than children who have not been securely attached as infants. Moreover, secure attachment can lead the child to be more comfortable in exploring, which leads to better learning and can lead to more intimate love relationships later in life.

Emptiness and hopelessness could be due to the neglect they had experienced from their own parents. Some of them were abandoned, totally forgotten and lived a life not knowing where they came from or who their real parents are. At other times, the parents may be physically present but love and care were not felt by them. As Belsky (1999) mentioned, when securely attached children reached adulthood, this mindset supposedly fostered a reproductive strategy that emphasized quality in mating relationships, more stable, durable romantic bonds, and more parental investment in offspring. Further, Belsky theorized that, historically, when parents are insensitive and unresponsive to infant's needs, the local environment was probably relatively unsafe and resources depleted.

Similarly, Durkheim (1982) mentions that individuals, like the informants, experience egoistic suicide resulting from little social integration. According to him, those individuals who were not sufficiently bound to social groups were left with little social support or guidance and, therefore, tended to commit suicide on an increased basis.

Most individuals ideating about suicide feel as though no one cares and they are alone so they resorted to drinking, smoking and even taking drugs. This could be due to apparent hopelessness and a feeling of depression. In one of the studies of Ruther and Soucar (2002), they pointed out that more or less, one of the most common predisposing factors for suicides is depression. Thus, the informants find their temporary refuge in joining parties and going out with friends to combat depression.

It is easy to talk about an ideal family and relationships that hypothetically work together in harmony. We, like the informants always dream to be in families that experience unity and harmony. However, Tumangday, (2000) observes that the importance of family is sometimes overlooked. Individual selfishness, conflict, unforgiving spirit, and stress can crowd out the family strengths that unity provides which was true with the informant's experience. Despite all these, they were able to recover and find meanings to life which is conceivably made possible by these "significant people" who cared so much. With the help of their friends, relatives, teachers and classmates, they started dreaming, wishing and planning for their lives. Young as they are. They also want to live a normal life away from discrimination hopelessness and fear.

People learn to cope with the problems and developed insights. This could be due to the lessons they learned from their bad experiences, the continued guidance from people around them and the realization that life is not all pains and hardships. This is consistent with Hurlock's (1982) statement that the human being is never static, change is constantly taking place in physical and psychological capacities. He asserts that the goal of developmental changes is to enable people to adapt to the environment in which they live. To achieve this goal, self-realization or sometimes called self-actualization, the urge to become the person, both physically and psychologically, that one wants to be. Similarly, Pervin (2001) opines that each stage brings psychosocial crises involving transitions in important social relationships and that personality is shaped by how individuals deal with these psychosocial crises. Each crisis is a potential turning point that can yield different outcomes.

There has been a felt need to have an organized program among the suicide attempters, however, lack of resources or the inability of the family to provide the needed interventions could be one of the reasons why suicide attempters do not receive 
immediate systematic organized interventions at all. Moreover, it could also be due to the fact that suicide is still considered a social stigma and like any disease must be kept within the family. Likewise, our culture and religion specifically Christianity has generally condemned suicide as a failure to uphold the sanctity of human life. Thus, this concern has been relegated to the background and would come every now and then.

Some people on the other hand, look at suicide as an ordinary thing that can be resolved even without medication or intervention.

\section{Mini-Theory: Card Tower Theory} presented.

Based on the findings and conclusions drawn from the study, this mini-theory is

The social investigation on the psychodynamics of suicide survivors converged at some common foci: familial arrangements such as growing up with broken or emotionally-distant families; unanswered emotional needs of affection, love and acceptance; overwhelming environmental pressures, triggered by persistent stressful events and unrewarded struggles with prospects of attaining control over self despite helplessness.

Considering the convergence, the overall upshot, the major triggering factors that led the suicide attempters to commit the act, delves on an individual's primary foundations. How their first few years of life have been, how their initial expectations were addressed, and how these individuals were cemented into the grounds of social relationships. Thus, the mini-theory termed as Card Tower Theory is proposed.

Card Tower Theory came from the idea on the nature of card towers. A bystander could not help but marvel how frail and thin playing cards can be constructed into skyscraping architecture. The bystander, however, would not dwell much on the idea that such card tower can topple down any second even with just a gush of wind. Just like suicide attempters, you cannot tell just by their appearance; they appear as normal and as average as any person would. Like tower cards, they may even appear to be a spectacle, living a lifestyle envied by many: good education, oligarch heritage. But since the foundation is weak, simply hardened paper and, thus, any force at par with the wind can destroy over what appeared to be once domineering tower.

For a tower to be sturdy and strong, an immensely firm foundation must be constructed. The same is true with human beings. The foundation encompasses a successful passage from Erik Erikson's Trust versus Mistrust; the basic needs of human love must have been met by none other than the primary social unit of an individual, the family. This developed trust will serve as a reserve fuel that in times when the person is in need of assurance, affirmation of love, he or she can still use that trust to overcome feelings of hopelessness. With a strong foundation, wherein familial love promises belongingness, an individual will have refuge in me-against-the world situations.

In addition, Sigmund Freud emphasized that a person's first years of life can be likened into a crystal ball that will foresee the person's future self. Thus, a someone said, "Our destinies are packaged in our childhood," having an intact family that adequately satisfies a child's cry for assurance, attention, and most importantly love will set a barricade to the potential insecurities. The card tower remains as several playing cards placed one on top of the other, never glued, never connected. Without a basic unit, such as a family, an individual may find it difficult to fix together bits and pieces of himself or herself since the very people who are actually tasked by nature to help are, as perceived by the individual, beyond his or her reach.

The card tower is said to be improving $\mathrm{s}$ it grows higher. The height will save the weak bottom. Just like the informants, their suicidal attempts are their own cry for attention, striving for superiority and struggle for power; because of their inner helplessness they strive to perform some deed that is seen inimical to their well-being.

Five major assumptions were derived from the entire social investigation and these are: (1) suicide attempters reveal a familial background that did not cater to their childhood needs of love and belongingness, (2) suicide attempters believe that the emptiness they have can be filled with their quest for attention and power and committing 
suicide is their primary way to gain such attention and power, (3) suicide attempters are identified to have not fully developed the initial sense of trust, (4) they are also overwhelmed by problems which they find themselves helpless, and (5) environmental pressures such as strained relationship and persistent stressful events like lack of care and parental guidance had pushed the attempters "over the up without love, care, attention from a family.

Indeed, a strong foundation is a prerequisite to a healthy growth and development of an individual otherwise it will topple even with just a slight pressure. It is the same with a hollow, empty, meaningless life of an individual who grows up without love, care and attention from a family.

Thus, the Card-Tower theory can be summarized into this statement: the Foundation is of utmost importance. It will either make or break a structure, whether it be cards or persons.

Based on the results and conclusions drawn from the study, the following recommendations are therefore advanced:

\section{For Families}

Studies of family relationships have revealed that all family relationships are important factors in the individual's development. Thus, a need for an open communication.

Parents need to establish affirm foundation especially in terms of establishing a good relationship with their children. Free and open communication with them is very important. Parents/Guardians must direct their children to the right path. They must rear them with love and commitment. They have to keep on trying to keep the marriage for the children. Although in some cases, when separation is inevitable, parents must still give what is due to their kids.

Family relationships play a dominant role in every child's life. Therefore, in the absence of a father or a mother, sufficient love and quality time must be given by the immediate family member. They have to value every child no matter how many they would be. The impact of one's parenting not only affects the children, but it can also affect the children's children for generations. Parents, therefore, must patiently listen to their children and must spend quality time with them.

Children need to communicate their thoughts and feelings to significant others, someone who can understand them. They should be reared in an environment full of love and trust.

\section{For Schools and Other Institutions}

In the absence of a family, children have the tendency to long for love and attention somewhere. Schools must offer programs that cater to the needs of the students, physically, emotionally, mentally, and spiritually.

Various suicide prevention programs and strategies must be implemented. There should be training for health professionals and employing of crisis counseling organizations.

\section{For Teachers}

Teachers, as alter ego of parents, must try to the best of their ability to fill what the family lacks to give these children.

It is recommended that part of the training for teachers is not only to develop the children's minds but also their worth as a person. They should guide an individual to learn to promote his emotional well-being.

As they are the ones who are in close contact with the students, they need to equip themselves with the necessary knowledge and skills to identify those who have suicidal tendencies and to come up with preventive measures. Furthermore, they can make referrals to the appropriate agencies or experts. 
The counselor can have interview sessions with students, family members, and friends, most often separately, and can make an assessment of the case and tailor the specific management regimen for the individual.

But they should not only wait for the students to go to their office they should device a pro-active program that caters to the needs of their students and to prevent suicide cases. Hence, a proposed intervention program is hereby included in this study with the hope to help adolescents who might be suffering from what is called "time of turmoil" or "teenage crisis".

\section{The Proposed Intervention Programs for Suicide Attempters}

Suicidal persons have been found to be people whose inner growth are stifled and too often failed to probe into their deeper selves in their struggles. This program centers on assisting these people to dream up personal strategies that do not only help in the short run but also bring them to get at deeper issues or match up with their current stage of coping in order for them to refrain from repeating suicidal attempts.

Program Assumptions

Suicidal persons like any other normal individuals facing overwhelming problems are capable to change their ways of responding to intent situations. What they need is to learn new ways of responding to the intent situations confronting them without choosing suicide as the permanent solution to their temporary problems. Learning is the fuel that will enable them to expand and find meaning in life and to get rid of being trapped in desperate situations.

The suicide attempters because of their intense feelings of being abandoned, loneliness, anger, or being ashamed of something, they need help from others, particularly their own families in order to regain the confidence and self-mastery that they need in order to attain success in their personal lives.

The study also showed that families of suicidal persons go through the stresses and strains like any other families. Yet some manage to produce self confident children who are capable of coping successfully even with the difficult environment. For this reason, the proposed program is banking on the family as the main context for the individual's behavior. The program aims to assist families in helping the suicidal families build confidence and ultimately self-mastery by improving communication and relationship.

Program Framework

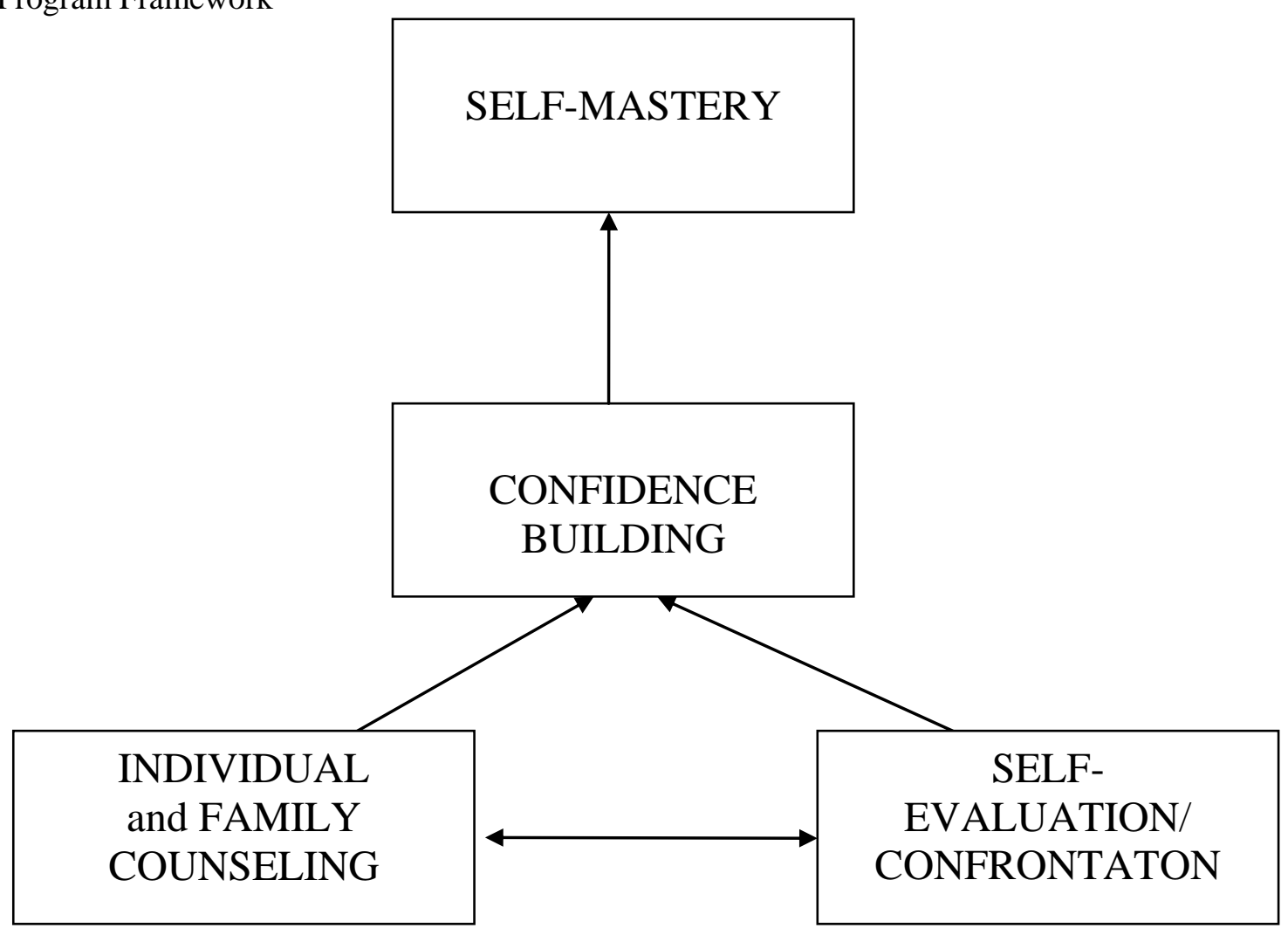


Major Program Concepts

This program will use the experiences of the person and the family for reflection in order to generate new insights. The Counselor's role is that of a facilitator.

\section{SELF-CONFRONTATION}

Psychologist O.H. Mower, admits tat there are many different reasons why people get into psychological and emotional trouble but suggests that one reason is related to lack of self-disclosure. Sidney Jourard, another psychologist, has a similar view. According to him, self-disclosure is absolutely necessary for psychological health and growth. People can't be themselves unless they know themselves. One of the best ways to get people to know themselves more deeply and fully is by shaping their inner selves with other people.

\section{FAMILY ENRICHMENT/COUNSELING}

This program in Pineda (2007) offers ways for suicidal persons to recover their lost childhood selves, and begin a journey of discovering their true selves with the help of their families. The most important aspect here is the understanding of the family members of how suicidal person lost his/her true self in the dysfunctional family system. This program shows how each person in a family plays a part in the whole system.

There is no place or group that can sustain the struggle toward healing of a broken self, except for the place or group that has created the person - his/her family.

\section{References}

Aquino and Kahayun (2000). General psychology. Quezon City: Rex Publishing.

Arellado, M.A. (2005). Coping with life after retirement. Unpublished Doctoral Dissertation, West Visayas State University, Iloilo City.

Arenas, A.C. (2004). Introduction to psychology: Understanding Human Behavior. Quezon City, Philippines: Rex Printing Company Inc.

Bucu, L.C., et al. (1981). Introduction to Psychology. Quezon City: Rex Publishing.

Busch, K.M.D. and Fawcett, Jan M.D. (2004). A Fine-Grained Study of Inpatients Who Commit Suicide. Psychiatric Annals34 (5).

Bruce, T.H. et al (2004). The Journal of the American Medical Association. 291 No (9) pg. 1031-1091.

Caldwell, C.B. and Gottesman, I.I. Schizophrenics kill themselves too. A review of risk factors for suicide. Schizophrenia Bulletin

Camarao, V. (2000). An Evaluation on the Counseling Service othe High Scool Guidance and Testing Center of St. Benedict College.

Carson, R.C. et al (2000). Abnormal Psychology and Modern Life $\left(11^{\text {th }}\right.$ edition) Philippines: Pearson Education Asia Pte. Ltd.

Caruncho, M.V. (2009). Biological Psychology Links: To Accompany Biological Psychology (Sixth Edition)

Durkheim, Emile (1982) The Rules of Sociological Method. Trans. W.D. Halls. New York: The Free Press.

Glaser, B \& Strauss, A.L. (1967). The Discovery of Grounded Theory: Strategies for Qualitative Research, Chicago, Aldine Publishing Company

Gaerlan, J., et al (2000) ( $5^{\text {th }}$ edition) General Psychology. Philippines: Ken Inc.

Gines, A.C., et al. (2001) Developmental Psychology. Quezon City; Philippines.

Gray, D.E. (2004) Doing Research in the Real World. SAGE Publication

Groenewoud, V. d. H. et. al. (2000). Clinical Problems with the Performance of Euthanasia and Physician-Assisted Suicide in the Netherlands. The New England Journal of Medicine. 292 (3) pg. 51-556.

Hall, S.G., (1904) Adolescence: A Centennial Reappraisal.

Halpen, D.F. (2001) Psychology: Themes and Variations. (5 ${ }^{\text {th }}$ edition). USA: Wadsworth.

Hurlock, E.B., (1982) Developmental Psychology: A Life Span Approach. New York: Mcgraw-Hill. 
Jick, Kaye, et al. (2004). Antidepressants and the Risk of Suicidal Behaviors. The Journal of the American Medical Association. 292 (3) pp. 338-343.

Juurlink, H. et. al. (2004). Medical Illness and the Risk of Suicide in the Elderly. Archives of Internal.164 (11).

Kobasa. S. (1979) Personality and Social Psychology Article.

Kosslyn, M. Resenburg, R. (2003) Fundamentals of Psychology: the brain, the person, the world. Boston mass: All and Bacon/Pearson Education (Grolier Inc., 1995, Health Practices Among Selected Families in Depressed Coastal Communities in Northern Antique by Phobe R. Tugon, Dec. 1999)

Lefton, L.A. (1994) Psychology. USA: Allyn and Bacon.

Nairne, J.S. (2003) Psychology of the Adaptive Mind ( $3^{\text {rd }}$ edition). USA: Wadsworth Thomson Learning.

Myers, D.G. (1992) Psychology USA: Worth Publisher Inc.

Otsubo, T. and Kamijima, K. (2004). Neuropsychiatric Symptoms Related to Interferon Therapy. Japan Medical Association Journal. 47 (2) pp. 73-78.

Percetakan S. (1997) Basic Facts About Psychiatric Illness. Dr. IC. Billar. Malaysia

Pervin, L. (2001) Personality theory and Research $8^{\text {th }}$ edition New York: John Wiley.

Pineda, L. (2007). The Struggles and pains of adult children: Basis for a family relationship enhancement program. Unpublished Undergraduate dissertation. West Visayas State University, Iloilo City

Rutter, P.A., Soucar E., (2004) Adolescence: adolescent suicide risk: Four psychosocial factors.

Sadock. B.J, (1998) Synopsis of Psychiatry: Behavioral Sciences, Clinical Psychiatry $8^{\text {th }}$ Edition

Tumangday, M. (2002) Home Builders: Enhancing Relationship with Your Spouse and Children. Philippine Publishing House

Tugon, P.R (1999) Health Practices among Selected Families in Depressed Costal Communities in Northern Antique: A Graduate Research Paper. WVSU: Graduate School

Villanueva, (1995), Coping Behavior and Family Structure of High School Students by Amabel Tangco-Siason

Siason, A. (2005) Coping behaviors and family structure of high school students.

Silverman, A (2005) Coping behaviors USA: McGraw-Hill Higher Education.

Santrock, J.W. (2000). Children. (6 $6^{\text {th }}$ edition) USA: McGraw-Hill Higher Education.

Taylor, S.E., et al. (1997) Social Psychology. USA: Prentice Hall.

Tsutsui, S. (2004). Management of Depression in Late Middle Age. Japan Medical Association Journal. Volume 47 (4) pp. 171-174.

Rogers 1959, Theories of Personality by Jess Feist 1994 by Holt, Rineahart and Winston, Inc.

Webster's Universal College Dictionary (2001) USA. Random House Inc.

Wood, R (1992). Legal Guide to Independent contractor Status, New York: John Wiley

Wood, S.E. and Wood, E.G. (1996). The World of Psychology ( $2^{\text {nd }}$ edition). USA: A simon and Schuster Company.

Zubin, J. and Spring, B. (1977) Vulnerability: A New View on Schizophrenia Journal of Abnormal Psychology 86, 103-126

http://en.wikipedia.org/wiki/Borderline_pesonality_disorder

http://www.suicide.org?bipolar-and-suicide.html

http://www.suicide.org/schizophrenia-and-suicide.html

http://www.suicide.org/postpartum-depression-and-suicide.html

www.ncptsd.v9.gov

http://www.cbsnews.com/stories/2003/10/28/60II/main580507.shtml

http://www.magicvalley.com/news/words/worldnation/index.asp

http://www.cnn.com/2004/HEALTH/03/22/antidepressant.warning.ap/index.html

http://www.usatoday.com/news/world/iraq/2004-01-14-military-suicide_x.htm 